\title{
Multiple introductions of serotype $O$ foot-and-mouth disease viruses into East Asia in 2010-2011
}

\author{
Begoña Valdazo-González ${ }^{1}$ Anna Timina ${ }^{2}$, Alexey Scherbakov², Nor Faizah Abdul-Hamid ${ }^{1,3}$, Nick J Knowles ${ }^{1}$ \\ and Donald P King ${ }^{1 *}$
}

\begin{abstract}
Foot-and-mouth disease virus (FMDV) is a highly contagious and genetically variable virus. Sporadic introductions of this virus into FMD-free countries may cause outbreaks with devastating consequences. In 2010 and 2011, incursions of the FMDV O/SEA/Mya-98 strain, normally restricted to countries in mainland Southeast Asia, caused extensive outbreaks across East Asia. In this study, 12 full genome FMDV sequences for representative samples collected from the People's Republic of China (PR China) including the Hong Kong Special Administrative Region (SAR), the Republic of Korea, the Democratic People's Republic of Korea, Japan, Mongolia and The Russian Federation were generated and compared with additional contemporary sequences from viruses within this lineage. These complete genomes were 8119 to 8193 nucleotides in length and differed at 1181 sites, sharing a nucleotide identity $\geq 91.0 \%$ and an amino acid identity $\geq 96.6 \%$. An unexpected deletion of 70 nucleotides within the $5^{\prime}$-untranslated region which resulted in a shorter predicted RNA stem-loop for the S-fragment was revealed in two sequences from PR China and Hong Kong SAR and five additional related samples from the region. Statistical parsimony and Bayesian phylogenetic analysis provide evidence that these outbreaks in East Asia were generated by two independent introductions of the O/SEA/Mya-98 lineage sometime between August 2008 and March 2010. The rapid emergence of these viruses from Southeast Asia highlights the importance of adopting approaches to closely monitor the spread of this lineage that now poses a threat to livestock industries in other regions.
\end{abstract}

\section{Introduction}

Foot-and-mouth disease (FMD) is a highly contagious viral disease characterized by rapid onset and high morbidity in a wide range of susceptible host species within the members of the order Artiodactyla (for reviews see $[1,2])$. The disease is endemic in the Middle East, Central and South Asia, Africa, and some countries in South America. FMD is notifiable to the World Organisation for Animal Health (OIE) and as a consequence FMD-affected countries have restricted trade in livestock and livestock products with FMD-free regions and countries. Therefore, an incursion of FMD into disease-free countries can have a devastating impact as was shown in the UK in 2001 [3] and 2007 [4], or in Taiwan during 1997 [5].

\footnotetext{
* Correspondence: donald.king@pirbright.ac.uk

'The Pirbright Institute, Ash Road, Pirbright, Surrey GU24 ONF, UK Full list of author information is available at the end of the article
}

FMD is caused by a non-enveloped picornavirus (FMDV: genus Aphthovirus) with icosahedral symmetry. The virion, approximately $30 \mathrm{~nm}$ diameter, contains a single-stranded positive-sense RNA genome of approximately 8500 nucleotides (nt) in length. It contains a single open reading frame which is flanked by $5^{\prime}$ and $3^{\prime}$ untranslated regions (UTRs) and encodes the four structural proteins which form the capsid [1A (also known as VP4); 1B (VP2); 1C (VP3) and 1D (VP1)], and ten non-structural proteins (L, 2A, 2B, 2C, $3 \mathrm{~A}, 3 \mathrm{~B} 1-3,3 \mathrm{C}$, and $3 \mathrm{D}$ ) (for reviews see [6,7]). FMDV is a rapidly evolving virus classified into seven distinct serotypes, i.e. O, A, C, Asia 1, and Southern African Territories (SAT) 1, SAT 2 and SAT 3, which are supported by genetic classification based on the VP1-coding region. Most of our knowledge about the global distribution and molecular epidemiology of the virus is dependent upon analysis of this region which comprises approximately $8 \%$ of the FMDV genome [8]. However, complete genome sequences

C Biomed Central

(c) 2013 Valdazo-González et al.; licensee BioMed Central Ltd. This is an Open Access article distributed under the terms of the Creative Commons Attribution License (http://creativecommons.org/licenses/by/2.0), which permits unrestricted use, distribution, and reproduction in any medium, provided the original work is properly cited. 
of FMDV are required to fully understand viral determinants of pathogenicity, virulence, host range and evolution. Moreover, complete genome sequence analysis of FMDV isolates has been successfully used to trace the origin and the transmission pathways of the virus within an outbreak [4,9-11].

During 2010-2011, incursions of the Mya-98 lineage of the Southeast Asia (SEA) topotype of serotype O (O/ SEA/Mya-98) caused a series of high profile FMD outbreaks across five East Asian countries: the People's Republic of China (PR China) including the Hong Kong Special Administrative Region (SAR), Japan, Mongolia, the Russian Federation (Russia) and the Republic of Korea (ROK; South Korea) [12-15]. A range of host species have been affected by these outbreaks including domesticated pigs, cattle and small ruminants, as well as evidence for infection in gazelles in Mongolia. Previous pandemic waves of FMD have affected many East Asian countries: during 1999-2002, the O/ME-SA/PanAsia lineage caused widespread outbreaks in PR China, ROK and Japan (in 1999-2000, 2000 and 2002 and 2000, respectively) prior to those in South Africa (2000) and Europe (2001) [3,16]. During 2005-2007, serotype Asia 1 also spread throughout many countries in the region (PR China, Mongolia, Russia, North Korea); although it was not possible to determine the precise origin of these outbreaks, Southeast Asia was not implicated [17]. In ROK and PR China the outbreaks due to O/SEA/Mya98 were preceded by FMD outbreaks due to serotype A (A/ASIA/Sea-97 lineage) [12]. Together, these recent events may be indicative of changing epidemiology of FMD in East Asia which may heighten risk for onward transmission to more distant countries including those that are FMD-free.

The aim of this study was to analyse the complete genomes of representative FMD viruses recovered from outbreaks during the pandemic of O/SEA/Mya-98 in East Asia and to compare them with sequences from viruses from Southeast Asia where this lineage is endemic [18]. Furthermore, previously uncharacterised FMD outbreaks due to serotype $\mathrm{O}$ also occurred during 2011 in the Democratic People's Republic of Korea (DRK; North Korea) and analysis of one of these samples are included in this report. This study investigates the origin and evolution of this emerging virus lineage.

\section{Materials and methods \\ Samples}

The clinical samples and isolates included in the present study are listed in Table 1 . They represent viruses within the O/SEA/Mya-98 lineage which affected eight East Asian countries during 2009-2011. These isolates were selected on basis of their VP1 sequence, previously described [12].

\section{Full genome amplification}

The FMDV amplification of 12 isolates was undertaken in two laboratories using the following approaches.

At The Pirbright Institute (PI, UK), the full genome of nine FMD viruses (Table 1) were amplified using a protocol initially developed to sequence related FMDV serotype O viruses from Southeast Asian countries [19]. Briefly, total RNA was extracted from the clinical samples or cell culture using RNeasy Mini Kit (Qiagen Ltd., Crawley, West Sussex, UK) according to the manufacturer's instructions. After reverse-transcription, using the UKFMD Rev 6 primer (5'-GGC GGC CGC TTT TTT TTT TTT TTT-3') and SuperScript ${ }^{\mathrm{TM}}$ III Reverse Transcriptase (Invitrogen, CA, USA), the viral cDNA was purified [Illustra ${ }^{\mathrm{TM}}$ GFX PCR DNA and Gel Band Purification Kit (GE Healthcare, Buckinghamshire, UK)] according to the manufacturer's instructions, and amplified using Platinum ${ }^{\bullet}$ High Fidelity Taq (Invitrogen, CA, USA) to generate 22 PCR overlapping fragments that ranged in length from approximately 330 to 700 base pairs.

At the FGI Federal Centre for Animal Health (ARRIAH), full genome sequencing was undertaken as follows. Briefly, total RNA was extracted from three cell culture isolates (Table 1) using Ribo-prep kit (ILS, Moscow, Russian Federation) according to the manufacturer's instructions. Reverse-transcription and PCR (variant "one tube - one buffer") were used to generate 18 overlapping fragments. To determine 5 ' - and $3{ }^{\prime}$-end sequences, RNA ligation was carried out using T4 RNA Ligase (Fermentas, Lithuania) in a protocol similar to one described previously [20]. Subsequently, a nested RT-PCR using forward primers for $3 \mathrm{D}$ region and reverse primers for the S-fragment was used to amplify a PCR-fragment consisting of approximately 155-160 nt (depending on poly (A) length) from the 3 '-end and 74 nt from the Sfragment of FMDV RNA.

\section{Amplification of the S-fragment of the 5'-UTR}

Nine additional clinical samples from animals infected within the O/SEA/Mya-98 outbreak in Hong Kong SAR (Table 1) were processed at the PI as previously described to generate the S-fragment of the $5^{\prime}$ UTR. The primers described in the full genome protocol to generate and sequence this region of the FMDV genome (i.e. O1F and O1R [19]), were used in parallel with a further reverse primer (i.e. O1F2: 5'-ACC GAC TAG TAC TCT TAA CAC TCC GC-3'), designed to target the deleted region within the S-fragment of the $5^{\prime}$ UTR. This last step was carried out to discard the hypothesis that the deletion in the S-fragment of the FMDV isolate $\mathrm{O} / \mathrm{HKN} / 20 / 2010$ was an artefact of the RT-PCR procedure either due to the passage of the virus in cell culture. 
Table 1 FMDV samples from the O/SEA/Mya98 lineage analysed in this study representing complete genomes (CG), S-fragments (S) and polyprotein open-reading frames (ORF) generated at the Pirbright Institute (PI) and the FGI Federal Centre for Animal Health (ARRIAH).

\begin{tabular}{|c|c|c|c|c|c|c|}
\hline & Isolate & Specimen & Location & Collection date & Host species & $\begin{array}{c}\text { GenBank accession number } \\
\text { (source laboratory for } \\
\text { novel data) }\end{array}$ \\
\hline CG & O/MAY/7/2007 & Cell culture & Melaka, Malaysia & 20/10/2007 & Cattle & HQ632772 \\
\hline CG & O/TAl/22/2009 & Fluid/cell culture & Lamphun, Thailand & 18/11/2009 & Swine & KF112879: This work (PI) \\
\hline CG & O/MYA/5/2009 & $\begin{array}{l}\text { Epithelial } \\
\text { suspension }\end{array}$ & Bago, Myanmar & 10/06/2009 & Cattle & KF112880: This work (PI) \\
\hline CG & O/MOG/7/2010 & $\begin{array}{l}\text { Epithelial } \\
\text { suspension }\end{array}$ & Sukhbaatar Province. Mongolia & 06/09/2010 & Cattle & KF112881: This work (PI) \\
\hline CG & $\begin{array}{l}\text { O/MOG/C-10/ } \\
2010\end{array}$ & Cell culture & Mongolia & $01 / 05 / 2010$ & Cattle & KF112882: This work (ARRIAH) \\
\hline CG & O/RUS/Jul 2010 & Cell culture & $\begin{array}{l}\text { Abagaytuy, Zabajkal'skij Kray, Chita } \\
\text { region, RF }\end{array}$ & 05/07/2010 & Swine & KF112883: This work (ARRIAH) \\
\hline CG & $\begin{array}{l}\text { O/RUS/Aug } \\
2010\end{array}$ & Cell culture & Zabajkal'skij Kray, Chita region, RF & $26 / 08 / 2010$ & Cattle & KF112884: This work (ARRIAH) \\
\hline$C G$ & O/JPN/1/2010 & Cell culture & Miyazaki Prefecture, Japan & $17 / 04 / 2010$ & Cattle & KF112885: This work (PI) \\
\hline CG & O/SKR/4/2010 & Fluid/Vesicular & Ganghwa, Incheon, ROK & 07/04/2010 & Cattle & KF112886: This work (PI) \\
\hline CG & O/SKR/5/2010 & Fluid vesicular & Andong, Gyeongbuk, ROK & 28/11/2010 & Swine & KF112887: This work (PI) \\
\hline CG & O/DRK/31/2011 & $\begin{array}{l}\text { Epithelial } \\
\text { suspension }\end{array}$ & Pyongan, DPRK & 01/01/2011 & Cattle & KF112888: This work (PI) \\
\hline$C G$ & $\mathrm{O} / \mathrm{BY} / \mathrm{CHA} / 2010$ & $\begin{array}{l}\text { Epithelial } \\
\text { suspension }\end{array}$ & $\begin{array}{c}\text { Baiyun district, Guangzhou city, } \\
\text { Guangdong, PRC }\end{array}$ & $15 / 03 / 2010$ & Swine & JN998085 \\
\hline CG & $\mathrm{O} / \mathrm{GZ} / \mathrm{CHA} / 2010$ & $\begin{array}{l}\text { Epithelial } \\
\text { suspension }\end{array}$ & Guanzhou, Jiangxi, PRC & $15 / 03 / 2010$ & Cattle & JN998086 \\
\hline$C G$ & O/GSLX/2010 & - & Linxia, Gansu, PRC & $30 / 06 / 2010$ & Swine & JQ900581 \\
\hline CG & $\begin{array}{c}\text { O/CHN/Mya98/ } \\
\text { 33-P }\end{array}$ & Cell culture & PRC & $30 / 06 / 2010$ & Cattle & JQ973889 \\
\hline$C G$ & $\mathrm{O} / \mathrm{HKN} / 15 / 2010$ & $\begin{array}{l}\text { Epithelial } \\
\text { suspension }\end{array}$ & Hong Kong SAR & $24 / 02 / 2010$ & Swine & KF112889: This work (PI) \\
\hline CG & $\mathrm{O} / \mathrm{HKN} / 20 / 2010$ & $\begin{array}{l}\text { Epithelial } \\
\text { suspension }\end{array}$ & Hong Kong SAR & 03/03/2010 & Swine & HM229661: This work (PI) \\
\hline $\mathrm{S}$ & O/HKN/1/2010 & $\begin{array}{l}\text { Epithelial } \\
\text { suspension }\end{array}$ & Hong Kong SAR & 05/02/2010 & Swine & KF112890: This work (PI) \\
\hline S & O/HKN/4/2010 & $\begin{array}{l}\text { Epithelial } \\
\text { suspension }\end{array}$ & Hong Kong SAR & $10 / 02 / 2010$ & Swine & KF112891: This work (PI) \\
\hline $\mathrm{S}$ & O/HKN/6/2010 & $\begin{array}{l}\text { Epithelial } \\
\text { suspension }\end{array}$ & Hong Kong SAR & $10 / 02 / 2010$ & Swine & KF112892: This work (PI) \\
\hline $\mathrm{S}$ & O/HKN/7/2010 & $\begin{array}{l}\text { Epithelial } \\
\text { suspension }\end{array}$ & Hong Kong SAR & $22 / 02 / 2010$ & Swine & KF112893: This work (PI) \\
\hline $\mathrm{S}$ & $\mathrm{O} / \mathrm{HKN} / 10 / 2010$ & $\begin{array}{l}\text { Epithelial } \\
\text { suspension }\end{array}$ & Hong Kong SAR & $24 / 02 / 2010$ & Swine & KF112894: This work (PI) \\
\hline S & $\mathrm{O} / \mathrm{HKN} / 12 / 2010$ & Pericardial fluid & Hong Kong SAR & $24 / 02 / 2010$ & Swine & KF112895: This work (PI) \\
\hline $\mathrm{S}$ & $\mathrm{O} / \mathrm{HKN} / 13 / 2010$ & $\begin{array}{l}\text { Epithelial } \\
\text { suspension }\end{array}$ & Hong Kong SAR & $24 / 02 / 2010$ & Swine & KF112896: This work (PI) \\
\hline S & $\mathrm{O} / \mathrm{HKN} / 18 / 2010$ & $\begin{array}{l}\text { Epithelial } \\
\text { suspension }\end{array}$ & Hong Kong SAR & 01/03/2010 & Swine & KF112897: This work (PI) \\
\hline S & O/HKN/19/2010 & Tissue & Hong Kong SAR & 03/03/2010 & Swine & KF112898: This work (PI) \\
\hline ORF & $\begin{array}{l}\text { O/NN/YB105/ } \\
2009\end{array}$ & Cell culture & Yen Bai, Vietnam & $17 / 09 / 2009$ & Buffalo & GU582115 \\
\hline ORF & $\begin{array}{l}\text { ONN/QB88/ } \\
2009\end{array}$ & Cell culture & Quang Binh, Vietnam & 09/11/2009 & Cattle & GU125650 \\
\hline
\end{tabular}


Table 1 FMDV samples from the O/SEA/Mya98 lineage analysed in this study representing complete genomes (CG), S-fragments (S) and polyprotein open-reading frames (ORF) generated at the Pirbright Institute (PI) and the FGI Federal Centre for Animal Health (ARRIAH). (Continued)

\begin{tabular}{|c|c|c|c|c|c|c|}
\hline ORF & $\begin{array}{c}\text { O/NN/LC169/ } \\
2009\end{array}$ & - & Lao Cai, Vietnam & 15/11/2009 & - & DQ119643 \\
\hline ORF & $\begin{array}{l}\text { ONN/GL13/ } \\
2006\end{array}$ & Cell culture & Gia Lai, Vietnam & $15 / 04 / 2006$ & Cattle & GU125648 \\
\hline ORF & ONN/SL01/2006 & Cell culture & Son La, Vietnam & 15/10/2006 & Buffalo & GU125649 \\
\hline ORF & ONN/SL21/2006 & Cell culture & Son La, Vietnam & $15 / 10 / 2006$ & Cattle & GU125647 \\
\hline ORF & ONN/SL22/2006 & Cell culture & Son La, Vietnam & 15/10/2006 & Cattle & HM05551C \\
\hline ORF & $\begin{array}{c}\text { O/HLJOC12/ } \\
2003\end{array}$ & - & Heilongjiang, PRC & $30 / 06 / 2003$ & - & DQ119643 \\
\hline
\end{tabular}

\section{DNA visualization and sequencing}

The PCR products were visualized on a $1.8 \%$ TBE agarose gel stained with ethidium bromide and purified using the same kit used for cDNA purification. Sequencing reactions were performed using the individual respective primers used for the amplification and Big Dye-Terminator v3.1 Cycle Sequencing Reaction Kit on an ABI 3730 DNA Analyser (Applied Biosystems, USA) following the manufacturer's instructions. Sequences were assembled, proof-read and edited with the Lasergene version 10.1 package (DNASTAR Inc, USA). These sequences were submitted to GenBank and were assigned the following accession numbers: HM229661, KF112879-KF112898.

\section{Computational analysis}

The sequences were compared with the complete genome sequences or sequences coding for the polyprotein of FMD viruses from the O/SEA/Mya-98 lineage obtained from other countries in East Asia such as the PR China, Malaysia and Vietnam which are available in GenBank (Table 1). Alignment of the sequences was performed using the ClustalW subroutine in BioEdit, Version 7.0.5.3 [21]. The same program was used to calculate the nucleotide and amino acid (aa) identity matrices.

Calculation of $\mathrm{dN} / \mathrm{dS}$ and detection of potential positive selection was carried out using using SNAP [22]. Potential recombination was checked using SimPlot version 3.5.1 [23]. The RNA structure of the S-fragment was reconstructed for $\mathrm{O} / \mathrm{HKN} / 20 / 2010, \mathrm{O} / \mathrm{HKN} / 15 /$ 2010 and O/TAI/22/2009 using RNAStructure v 3.5 [24] and RNAdraw version 1.1 [25].

Maximum-likelihood trees (1000 bootstrap replications) optimized using the heuristic nearest-neighbour -interchange method as implemented by the software program MEGA version 5.10 [26] were calculated using the S-fragment and the VP1-coding sequence. Maximum parsimony analyses using full genome sequences were carried out as implemented in TCS freeware, version
1.21 [27] following formatting using DnaSP, Version 4.10.3 [28]. The General Time Reversible (GTR) model (with no invariant sites) of nucleotide substitution was selected using jModelTest [29]. Bayesian evolutionary analysis using Markov chain Monte Carlo (MCMC) sampling bases (100 000 trees from 100 million generations), as implemented using BEAST software, version 1.6.1. [30], was carried out using the sequence coding for the polyprotein to estimate the rate of molecular evolution, to infer phylogenetic relationships and to implement the genetic temporal reconstruction of the outbreaks. Sampling collection dates were used to calibrate the molecular clock. The robustness of the parameters was assessed by substituting different combinations of molecular clocks and demographic models. The resulting output was checked in Tracer, version 1.5 [31] and visualized with FigTree, version 1.3.1. [32].

\section{Results}

\section{RT-PCR and sequencing}

A total of 12 full genome sequences belonging to the O/SEA/Mya-98 lineage of FMDV collected from eight Eastern Asia countries during 2009-2011 were obtained using an overlapping PCR strategy. All of the component PCR products were of the expected size and no evidence of cross-contamination was detected within the negative control RT-PCR reactions which were performed in parallel. Sequencing coverage for these consensus sequences (total number of sequenced nucleotides divided by the contig length) was $>3.5$.

The novel sequences generated in this study were compared with additional FMDV sequences (five full genome sequences and eight more sequences coding for the virus polyprotein) from the same lineage available in GenBank. In total, 17 full genome sequences and 25 sequences coding for the polyprotein of FMDVs belonging to the O/SEA/Mya-98 lineage recovered from outbreaks in the PR China and Hong Kong SAR, ROK, DRK, Japan, Mongolia, Russia, Thailand, Malaysia, Myanmar 
and Vietnam during 2003-2011 (Table 1) were included in the following analysis.

\section{Analysis of the full genome sequences}

The length of the 12 generated sequences ranged from 8123 to $8192 \mathrm{nt}$ which for the nine sequences generated at the PI included 44-55 nt derived from the PCR primers, a 10-nt artificial internal $\operatorname{poly}(\mathrm{C})$ tract within the $5^{\prime}$ UTR and a 10-nt artificial poly(A) tail at the 3 ' terminus of the virus. For the three genomes characterised at ARRIAH, only the poly $(\mathrm{C})$ tract sequences were artificial, while the poly (A) tract was truncated to 10 nucleotides in length. Only three ambiguities in two sequences $(\mathrm{O} / \mathrm{JPN} / 1 / 2010$ and O/MYA/5/2009) were found: $\mathrm{R}(\mathrm{A} / \mathrm{G})$ and $\mathrm{Y}(\mathrm{C} / \mathrm{T})$ at positions 2180 and 2182 , respectively, in the first sequence; and $\mathrm{R}(\mathrm{A} / \mathrm{G})$ at position 5792 in the second sequence.

The alignment of the 12 generated sequences and those available in GenBank (17 full genome sequences, 8124 sites; 8032 sites excluding sites with gaps) revealed 1186 nt substitutions at 1146 sites (Figure 1a). These substitutions were distributed across the genome $(0.14$ nt substitutions per nt sequenced) although rates in individual genomic regions varied from 0.25 substitutions per nt sequenced for the 3' UTR to 0.15 (substitutions per nt sequenced) for the 5' UTR. Within the structural proteins, VP4 had the lowest nt rate $(0.10)$ compared to VP2 (0.13), VP1 (0.16) and VP3 (0.16). Pairwise comparisons between sequences are shown in Additional file 1 . Nucleotide sequence identity ranged from $91.0 \%$ to 99.3\% while predicted aa identity ranged from $96.6 \%$ to 99.5\%. There was no clear evidence of recombination within these sequences or between these sequences and those available in GenBank (using SimPlot version 3.5.1; data not shown).

Within the open reading frame encoding the FMDV polyprotein, which ranged from 2331 to 2333 aa length, there were 173 aa substitutions. The difference in aa length was due to a single codon insertion in the sequences for O/GSLX/2010 and O/HKN/20/2010 after position 9 of the polyprotein and a single codon deletion in the sequences for $\mathrm{O} / \mathrm{SKR} / 4 / 2010$ and $\mathrm{O} / \mathrm{CHN} /$ Mya98/33-P at position 28 of the polyprotein. The coding region of the $\mathrm{L}$ protein had the highest aa

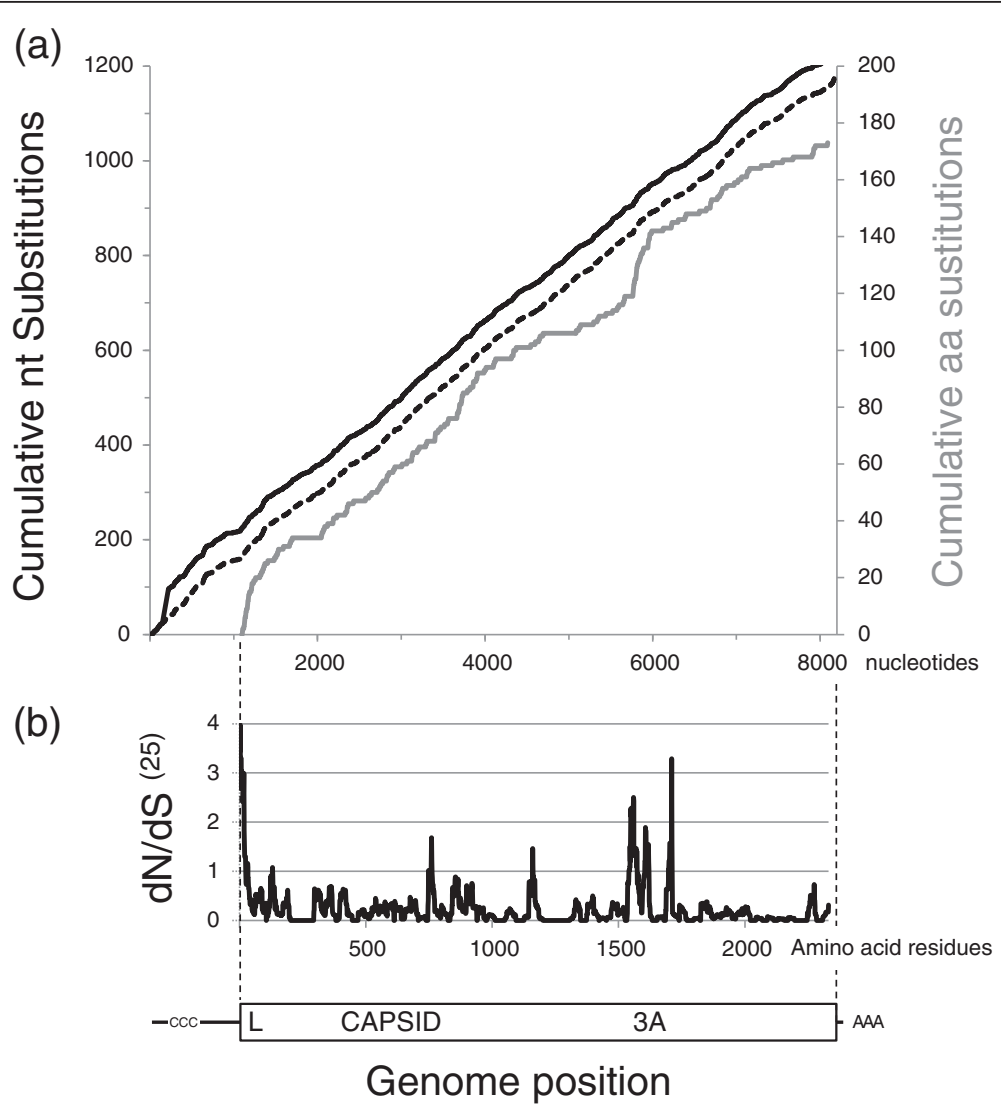

Figure 1 Nucleotide and amino acid variability of the 17 O/SEA/Mya-98 FMDV genome sequences obtained from East Asia. Graph (a) shows cumulative nucleotide (including [black] and excluding [black dots] the gap in the S fragment of the 5'- UTR) and amino acid (grey) substitutions against nucleotides occurring along the genome. Synonymous and nonsynonymous substitutions (mean values from a window of 25 residues sliding by an increment of one-codon) across the genome are also shown (b). 
substitution rate $[0.17$ substitutions per aa sequenced, higher $(P<0.05)$ than the most variable of the structural proteins] followed by VP1 (0.11) and 3B (0.15) as clearly visualised in the cumulative amino acid substitution plot in Figure 1a. Moreover, analysis of the synonymous versus non-synonymous ratio $(\mathrm{dS} / \mathrm{dN})$ also highlighted equivalent regions within $\mathrm{L}, \mathrm{VP} 1,3 \mathrm{~B}$ as well as $2 \mathrm{C}, 3 \mathrm{~A}$ and $3 \mathrm{C}$ where there was evidence of positive selection (Figure 1b).

\section{S-fragment (5' UTR)}

A 70 nt deletion in the S-fragment (5' UTR) was revealed in the sequences $\mathrm{O} / \mathrm{HKN} / 20 / 2010$ and O/GSLX/ 2010 (JQ900581) which was located at positions corresponding to nt $148-217$ of $\mathrm{O} / \mathrm{HKN} / 15 / 2010$. This unexpected deletion (Figure 2a) was subsequently found in five out of nine closely related field samples from Hong Kong SAR selected by phylogenetic analysis of the VP1 region. RT-PCR results using two forward different primers (O1F and O1F2) yielded negative results when using the forward primer targeting this fragment in those viruses with the deletion (O1F2, Figure $2 \mathrm{~b}$ ) whilst positive for those viruses without the deletion, therefore discarding the hypothesis that such a deletion was an artefact of the RT-PCR procedure or due to the passage of the virus in cell culture. Moreover, identical Sfragment sequences were obtained for $\mathrm{O} / \mathrm{HKN} / 20 / 2010$ when using epithelium suspension and cell culture as starting material. The reconstruction of the predicted secondary structure of the S-fragment for $\mathrm{O} / \mathrm{HKN} / 20$ /

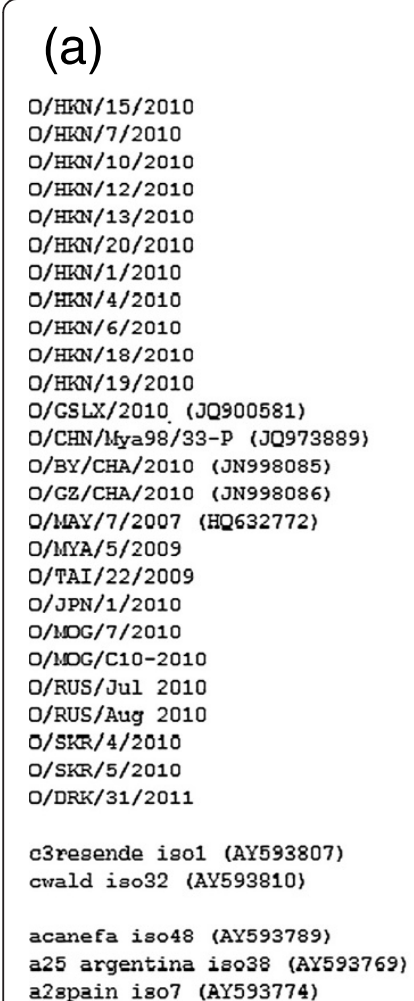

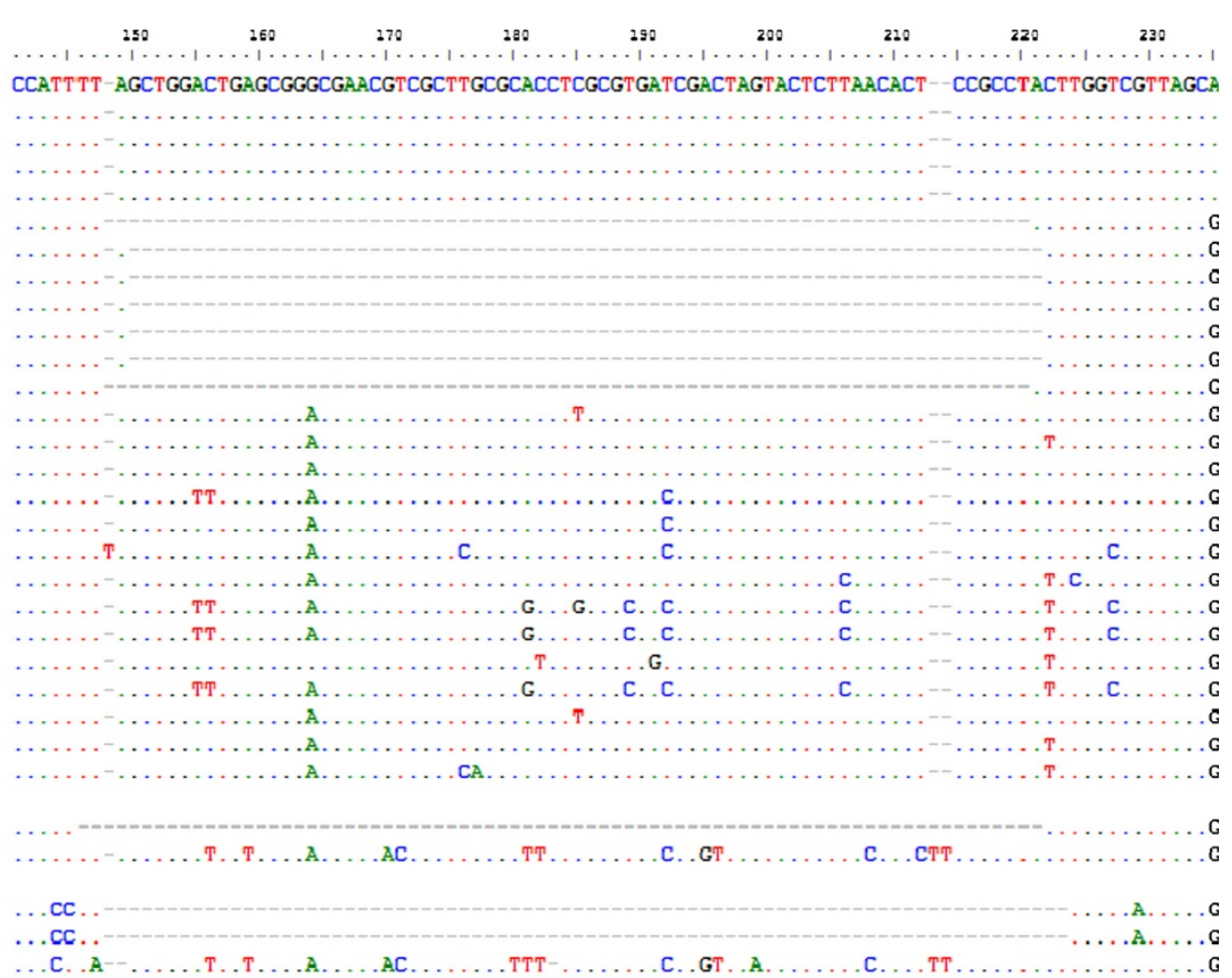

(b)

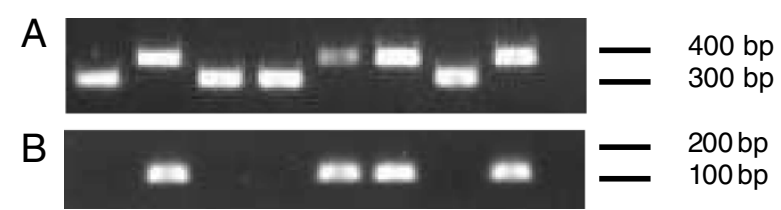

Figure 2 Deletion in the S-fragment of the genome of some FMDVs belonging to the O/SEA/Mya-98 lineage. a) Sequence alignment showing the deletion in the genome of some FMDVs belonging to the O/SEA/Mya- (70 nt length versus viruses from the same region and year) and other FMDV genomes available in GenBank. Sequences represented by names in lower case are derived from cell culture isolates generated

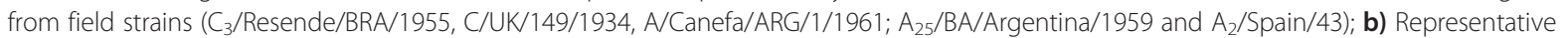
results for RT-PCR amplification of the S-fragment of O/HKN/20/2010 and other related viruses from Hong Kong SAR; A) The use of the primer pairs O1F/O1R amplified two different products of approximately 310 and $380 \mathrm{bp}$ depending on the presence or absence of the deletion, respectively. B) The amplification of the S-fragment of those viruses with a deletion failed when replacing the forward primer for a new primer (O1F2: 5'-ACC GAC TAG TAC TCT TAA CAC TCC GC-3') targeting this specific region. 
2010 showed a single stem-loop which only 35 pairs shorter in the apex than the one for O/HKN/15/2010, O/TAI/22/2009 (Figure 3).

\section{Maximum likelihood analysis (S-fragment and VP1 coding regions)}

Phylogenetic analysis using sequences for the Sfragment of these viruses together with viruses from other FMDV serotypes in which a similar deletion is present showed that all East Asian isolates (whether they have or do not have the deletion) clustered together with other viruses within the O/SEA/Mya-98a lineage
(Figure 4a) and were not closely related to other sequences from other serotypes with the deletion. Furthermore, Hong Kong SAR and Chinese viruses with the S-fragment deletion were also clustered closely together within the O/SEA/Mya-98a lineage as shown by analysis of the VP1 coding region (Figure $4 \mathrm{~b}$ ).

\section{Statistical parsimony analysis (17 full genome sequences)}

Analysis implemented by TCS allowed differences between these closely related individual sequences to be clearly visualised. Samples from the outbreaks in East Asian countries clustered into two different groups

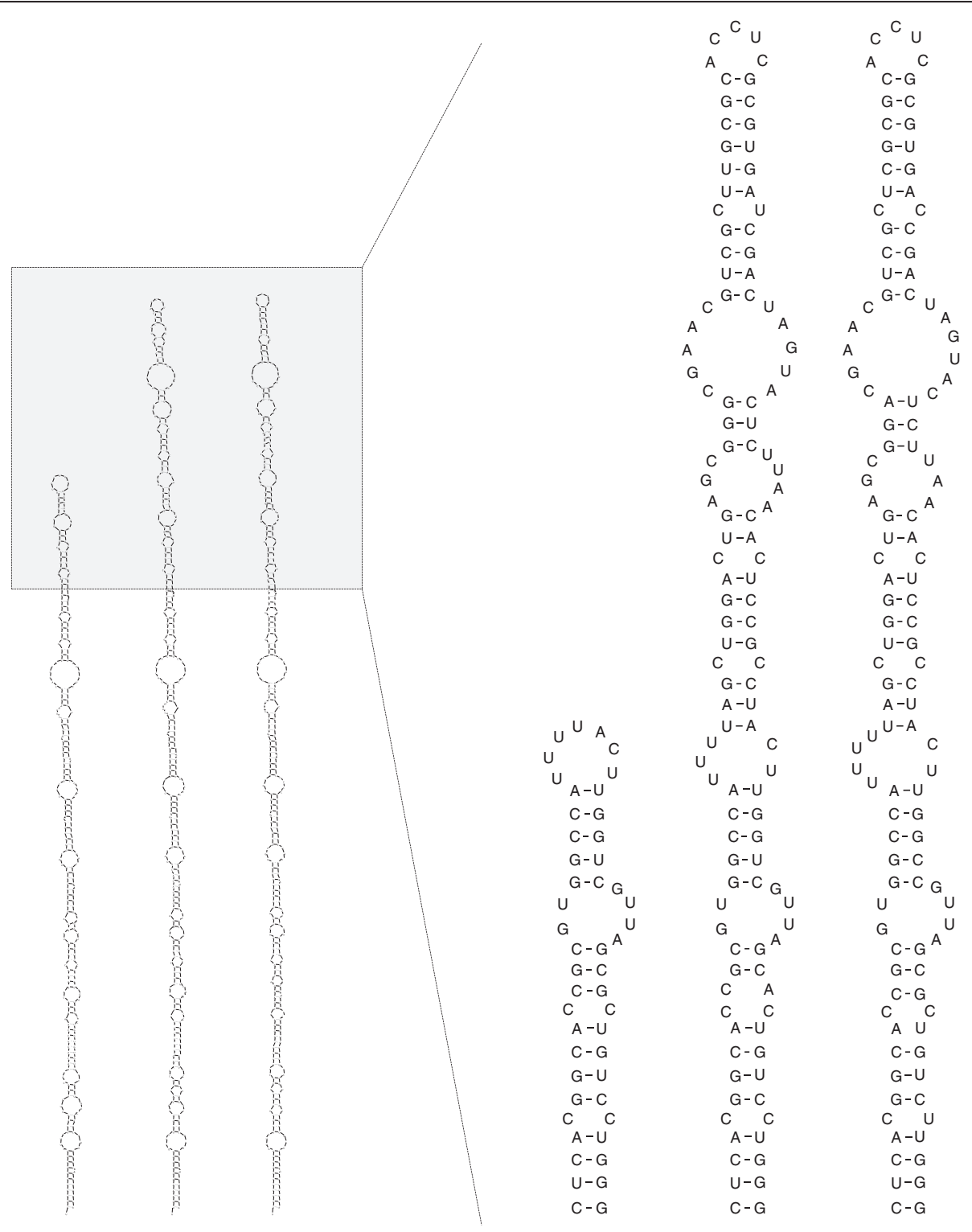
(a)
(b)
(c)
(a)
(b)
(c)

Figure 3 Predicted secondary structure of the S-fragment of selected O/SEA/Mya-98 viruses. The figure shows results corresponding to nucleotide positions 1-369 of TAl/22/2009 for (a) O/HKN/20/2010, (b) O/HKN/15/2010 and (c) O/TAl/22/2009. 


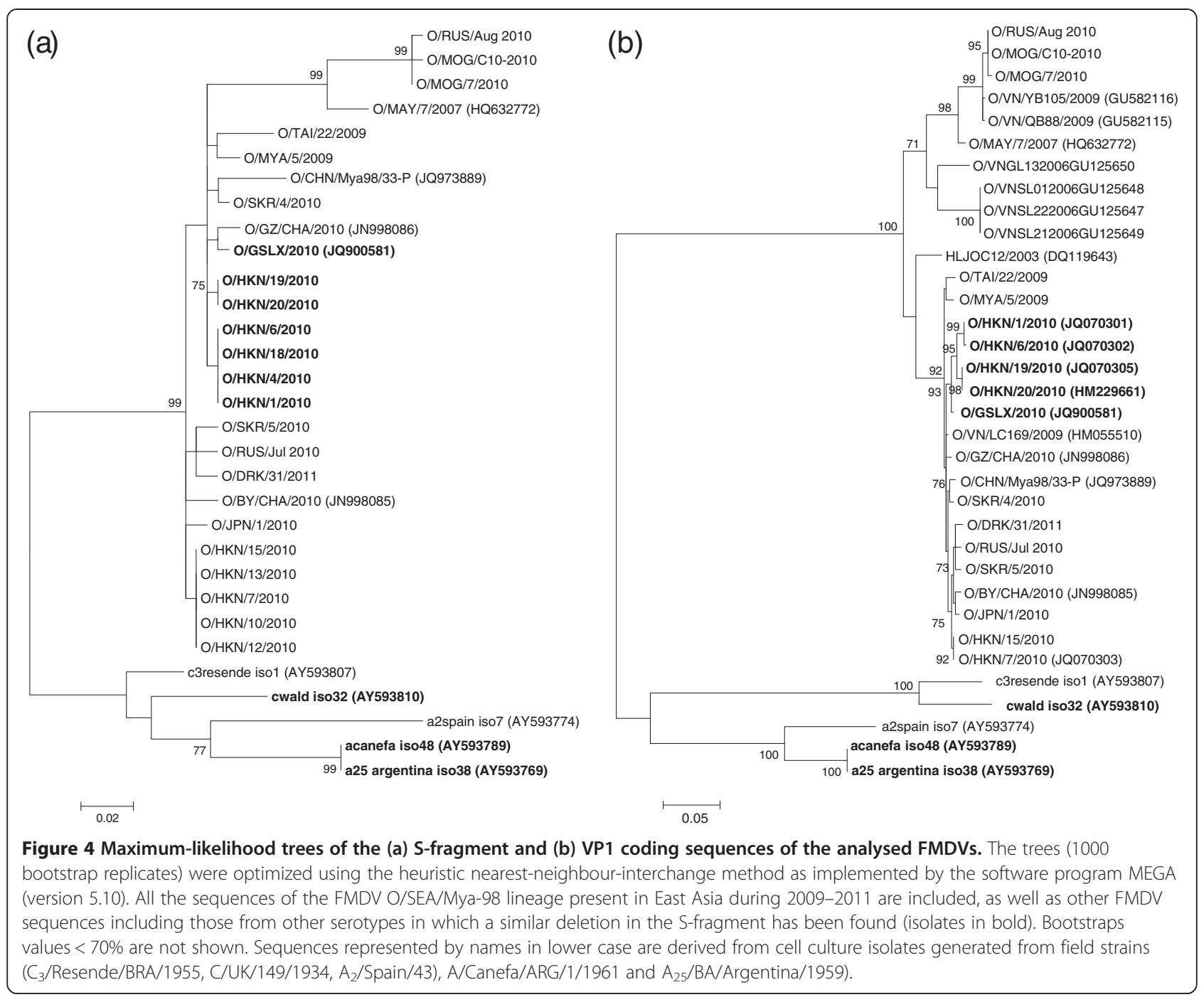

separated by more than 700 nt substitutions (Figure 5). Sequences from outbreaks in Southeast Asia, where FMDV is endemic, linked these two clusters. The groups containing these sequences did not necessarily conform to the geographical distribution of the sampling sites. The sequences from outbreaks in Thailand and Myanmar in 2009 were the closest to those causing outbreaks in the PR China and Hong Kong SAR, ROK, DRK, Japan and Russia during July 2010. The sequence from Malaysia in 2007 (O/MAY/7/2007) was the closest sequence to the viruses causing outbreaks in Mongolia and Russia during 2010.

\section{Markov chain Monte Carlo (MCMC) analysis (25 polyprotein sequences)}

A Bayesian phylogenetic tree (GTR substitution model, relaxed clock, constant population, 100000 trees from 100 million generations) using the polyprotein of 25 O/SEA/Mya-98 FMD viruses revealed a similar topology to that generated using statistical parsimony and full genome sequences (Figure 6). The rate of nucleotide substitutions (per site per year) was $4.94 \times 10^{-3}(95 \%$ highest posterior density - HPD: $3.40 \times 10^{-3}-6.58 \times 10^{-3}$ ) which are comparable to the rates observed during the FMDV outbreaks in UK during 2001 and 2007 [4,9,33] and Bulgaria in 2011 [11]. The most recent common ancestor (MRCA) was estimated to be in the 1990s $\left(21^{\text {st }}\right.$ February 1995; 95\% HPD: $26^{\text {th }}$ October $1990-16^{\text {th }}$ April 1999, dark blue bar, Figure 6). The recent outbreaks occurring in the Far East during 2010 and 2011 in East Asia represented two separate clusters of the O/SEA/ Mya-98 lineage (which we propose to name Mya-98a and Mya-98b). The isolates from PR China including Hong Kong SAR, ROK, DRK, Japan, and one from Russia (July 2010) and Vietnam (2009) (Mya-98a) shared a common ancestor estimated at the $19^{\text {th }}$ January 2009 (95\% HPD: $3^{\text {rd }}$ August $2008-17^{\text {th }}$ July 2009; light green bar) and were derived from another ancestor common 


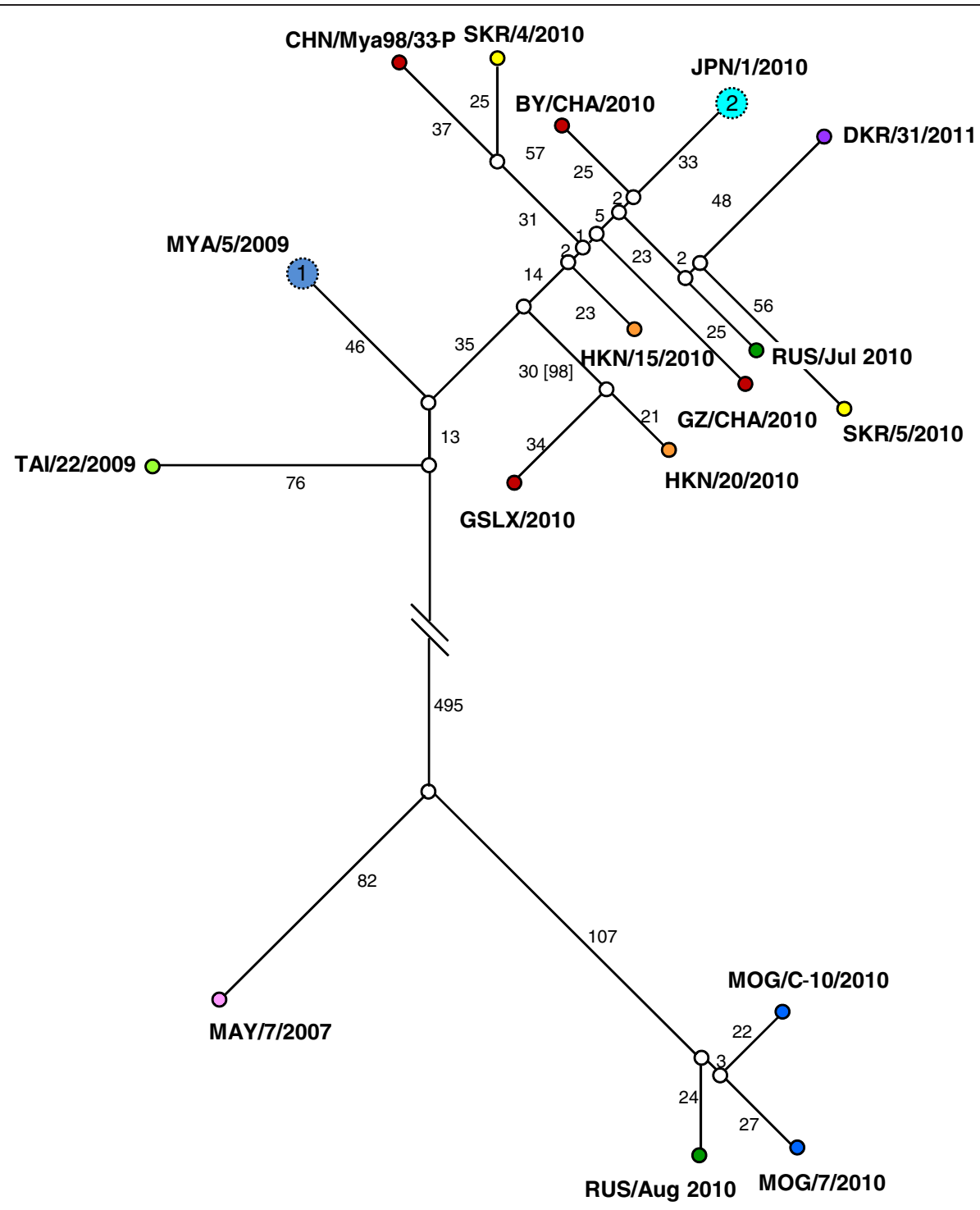

Figure 5 Statistical parsimony tree as implemented by TCS using 17 full genomes of the O/SEA/Mya-98 lineage. Representative FMD viruses causing the outbreaks in the Far East (during 2010 and 2011) are included together with three additional sequences of related viruses collected from countries (each coloured differently) where this strain is normally endemic (MAY/7/2007, MYA/5/2009 and TAl/22/2009). The number of putative nucleotide intermediates is shown for each of the branches which are drawn to scale (in brackets, number of nucleotide differences including the deletion in the 5' UTR). Genomes that contained consensus-sequence ambiguities are shown as larger circles (labelled with the actual number of ambiguities that were present), which are linked to other genomes via the closest sequence contained within the population.

with an isolate from Myanmar (2009) estimated on the $28^{\text {th }}$ February 2008 (95\% HPD: $6^{\text {th }}$ June $2007-3^{\text {rd }}$ November 2008, dark green bar). In contrast, the isolates from Mongolia and the other isolate from Russia (August 2010) (Mya-98b) were derived from a common ancestor estimated on the $13^{\text {th }}$ December 2009 (95\% HPD: 20th September 2009 - 3rd March 2010, light orange bar) which was derived from a common ancestor shared with isolates from Vietnam 2009 estimated on the $1^{\text {st }}$ April 2009 (95\% HPD: $20^{\text {th }}$ December $2008-5^{\text {th }}$ July 2009 , dark orange bar).

\section{Discussion}

Full genome sequencing data can be used to identify the origin, to reconstruct the transmission pathways and to detect undisclosed infection within field outbreaks of FMDV, as demonstrated in previous studies [4,9-11]. These data were analysed using different methods (TCS, Maximum Likelihood and Bayesian methods) providing complementary information that was used to increase the knowledge of the epidemiology of FMD in the region. The results from these different analyses were consistent and supported the occurrence of multiple 


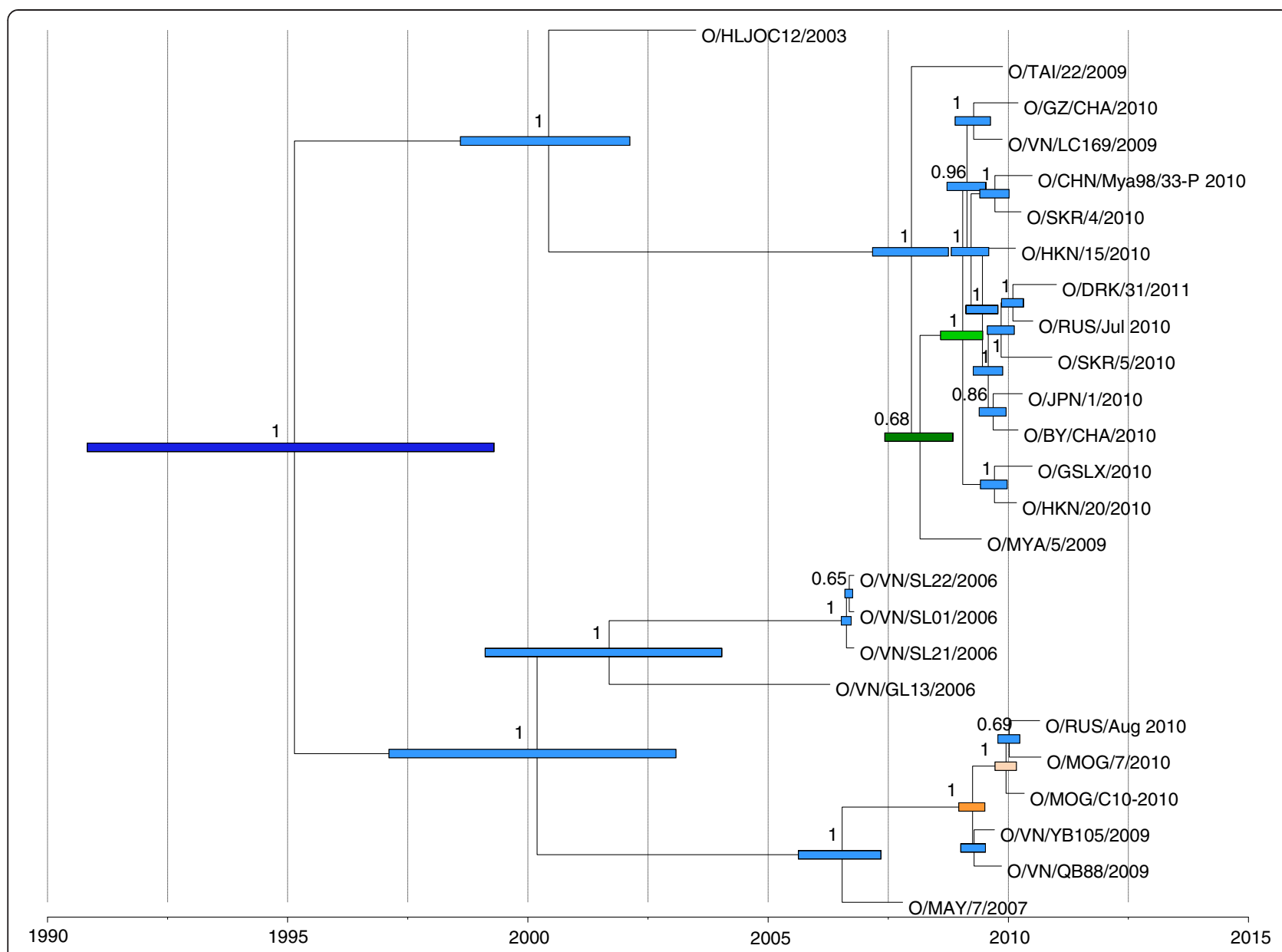

Figure 6 Bayesian maximum-clade-credibility time-scaled phylogenetic tree (BEAST) using the polyprotein of 25 O/SEA/Mya-98 FMD viruses. Uncertainty for the date of each node (95\% highest posterior density - HPD - intervals) is displayed in bars (different colours for the MRCA and ancestors of different O/SEA/Mya-98 FMD sub-lineages). Only node labels with posterior probabilities $>0.6$ are indicated.

independent virus introductions into some of the affected countries. This is most evident for sequences recovered from the Russian Federation, which were from two different O/SEA/Mya-98 genetic lineages. Furthermore, two sequences of FMD viruses sampled in ROK did not cluster together and were more closely related to other viruses from different countries in the region (Figure 5). The on-going risk of FMDV re-introduction influences the strategies used to control FMD. Although ROK previously held the OIE status of FMD-free without vaccination, the characterisation of these recent outbreaks has led to the use of a wide-scale vaccination programme in the country in order to adopt FMD freedom with vaccination [15]. All the viruses sequenced in this study share origins in Southeast Asia where this lineage is endemic. Certainly, the Mya-98a and Mya-98b lineages described in this paper have arisen due to at least two separate introductions into FMD-free countries in East Asia. Based upon our knowledge of previously characterised outbreaks $[4,11]$, it is also clear that a large number of unsampled FMD cases must have occurred in order to explain the observed genetic diversity between these viruses. This data does not categorically define the number of virus introductions into East Asia, and it is now critical that further characterisation of additional samples is undertaken to further understand the epidemiology of FMD in the region to establish and reinforce control measures.

A 70 nt deletion in the S-fragment ( $5^{\prime}$ UTR) was revealed in the sequences O/HKN/20/2010 and O/GSLX/ 2010 (JQ900581) which was located at positions corresponding to nt 148-217 of O/HKN/15/2010. This deletion has not been reported previously for any serotype $\mathrm{O}$ sequence or for any FMD virus in Asia. However, previous comparative genomic studies of FMDV [7] have highlighted two instances of similar deletions for serotype A isolates from Argentina in 1959 and 1961 (AY593769 and AY593789) and one additional serotype C isolate from the UK in 1934 (AY593810). Likewise, a $41 \mathrm{nt}$ deletion within the same region was found for 
serotype A viruses from India in 2009 (HQ832592) [34]. The results obtained in the present study using maximum likelihood analysis of the S-fragment and the VP1-coding region of isolates with and without deletions indicate that this deletion has arisen independently in these different serotypes and have not been transferred via recombination from a single event generated in one common ancestor. The deletion is neither host-species dependent, since they have been observed in viruses recovered from both pigs (East Asia) and cattle (India, South America and Europe). The reconstruction of the predicted secondary structure of the S-fragment for $\mathrm{O} / \mathrm{HKN} / 20 / 2010$ showed a single stem-loop which was only 35 pairs shorter in the apex than the one for $\mathrm{O} / \mathrm{HKN} / 15 / 2010, \mathrm{O} / \mathrm{TAI} / 22 / 2009$ and many other FMD viruses [35,36]. Earlier studies have suggested that the $\mathrm{S}$-fragment plays a role in viral replication, as well as contributing to pathogenesis [37]. However, further studies are required to determine the cause and the consequence of these changes impact upon the viral phenotype.

\section{Additional file}

Additional file 1: Nucleotide and amino acid identities for FMDV sequences. Table shows percent identities for nucleotides (across the genome) and amino acids (throughout the polyprotein).

Competing interests

The authors declare that they have no competing interests.

\section{Authors' contributions}

All authors contributed to the design of the study. BVG, NFAH, AS and AT carried out the experimental studies; BVG, NFAH, AS, NJK and DPK carried out the molecular analyses; BVG and DPK drafted the manuscript: All authors read and approved the manuscript.

\section{Acknowledgements \\ This project was supported by the Department for Environment, Food and Rural Affairs (Defra, United Kingdom; Research grant no. SE2938), The European Commission for the Control of Foot-and-Mouth disease (FAO/ EuFMD, Project PR 41764) and Epizone (EPIZONE IC4.7). Nor Faizah Abdul-Hamid was funded by a MPhil studentship from the Malaysian Government. The authors would like to acknowledge our colleagues in the Hong Kong Special Administrative Region (People's Republic of China), Republic of Korea, the Democratic People's Republic of Korea, Japan, Mongolia, Thailand and Myanmar for providing the samples; Nigel Ferris and Geoff Hutchings and staff in the WRLFMD, Pirbright Institute for processing of the original epithelium suspensions and preparing cell culture isolates, and Müge Firat-Sarac, Jemma Wadsworth, Jijun He and Youjun Shang for assistance in performing the sequencing protocols.}

\section{Author details}

${ }^{1}$ The Pirbright Institute, Ash Road, Pirbright, Surrey GU24 ONF, UK. ${ }^{2} \mathrm{FGI}$ Federal Centre for Animal Health, Vladimir, Russian Federation. ${ }^{3}$ Department of Veterinary Services, Wisma Tani, Block Podium, Lot 4G1, Precinct 4 Federal Government Administration Centre, Putrajaya 62630, Malaysia.

Received: 23 May 2013 Accepted: 21 August 2013

Published: 5 September 2013

\section{References}

1. Alexandersen S, Zhang Z, Donaldson Al, Garland AJ: The pathogenesis and diagnosis of foot-and-mouth disease. J Comp Pathol 2003, 129:1-36.

2. Grubman MJ, Baxt B: Foot-and-mouth disease. Clin Microbiol Rev 2004, 17:465-493.

3. Thompson D, Muriel P, Russell D, Osborne P, Bromley A, Rowland M, CreighTyte S, Brown C: Economic costs of the foot and mouth disease outbreak in the United Kingdom in 2001. Rev Sci Tech 2002, 21:675-687.

4. Cottam EM, Wadsworth J, Shaw AE, Rowlands RJ, Goatley L, Maan S, Maan NS, Mertens PP, Ebert K, Li Y, Ryan ED, Juleff N, Ferris NP, Wilesmith JW, Haydon DT, King DP, Paton DJ, Knowles NJ: Transmission pathways of foot-and-mouth disease virus in the United Kingdom in 2007. PLoS Pathog 2008, 4:e1000050.

5. Yang PC, Chu RM, Chung WB, Sung HT: Epidemiological characteristics and financial costs of the 1997 foot-and-mouth disease epidemic in Taiwan. Vet Rec 1999, 145:731-734.

6. Mason PW, Grubman MJ, Baxt B: Molecular basis of pathogenesis of FMDV. Virus Res 2003, 91:9-32.

7. Carrillo C, Tulman ER, Delhon G, Lu Z, Carreno A, Vagnozzi A, Kutish GF, Rock DL: Comparative genomics of foot-and-mouth disease virus. J Virol 2005, 79:6487-6504.

8. Knowles NJ, Samuel AR: Molecular epidemiology of foot-and-mouth disease virus. Virus Res 2003, 91:65-80.

9. Cottam EM, Haydon DT, Paton DJ, Gloster J, Wilesmith JW, Ferris NP, Hutchings GH, King DP: Molecular epidemiology of the foot-and-mouth disease virus outbreak in the United Kingdom in 2001. J Virol 2006, 80:11274-11282

10. Konig GA, Cottam EM, Upadhyaya S, Gloster J, Mansley LM, Haydon DT, King DP: Sequence data and evidence of possible airborne spread in the 2001 foot-and-mouth disease epidemic in the UK. Vet Rec 2009, 165:410-411.

11. Valdazo-Gonzalez B, Polihronova L, Alexandrov T, Normann P, Knowles NJ, Hammond JM, Georgiev GK, Ozyoruk F, Sumption KJ, Belsham GJ, King DP: Reconstruction of the transmission history of RNA virus outbreaks using full genome sequences: foot-and-mouth disease virus in Bulgaria in 2011. PLoS One 2012, 7:e49650

12. Knowles NJ, He J, Shang Y, Wadsworth J, Valdazo-Gonzalez B, Onosato H, Fukai K, Morioka K, Yoshida K, Cho IS, Kim SM, Park JH, Lee KN, Luk G, Borisov V, Scherbakov A, Timina A, Bold D, Nguyen T, Paton DJ, Hammond JM, Liu X, King DP: Southeast Asian foot-and-mouth disease viruses in Eastern Asia. Emerg Infect Dis 2012, 18:499-501.

13. Park JH, Lee KN, Ko YJ, Kim SM, Lee HS, Park JY, Yeh JY, Kim MJ, Lee YH, Sohn HJ, Moon JS, Cho IS, Kim B: Outbreaks and diagnosis of foot-and -mouth disease serotype $\mathrm{O}$ in the Republic of Korea, April-June 2010. Transbound Emerg Dis. in press.

14. Muroga N, Hayama Y, Yamamoto T, Kurogi A, Tsuda T, Tsutsui T: The 2010 foot-and-mouth disease epidemic in Japan. J Vet Med Sci 2012, 74:399-404

15. Lee HS, Lee NH, Seo MG, Ko YJ, Kim B, Lee JB, Kim JS, Park S, Shin YK: Serological responses after vaccination of growing pigs with foot-and -mouth disease trivalent (type O, A and Asia1) vaccine. Vet Microbio 2013, 164:239-245.

16. Knowles NJ, Samuel AR, Davies PR, Midgley RJ, Valarcher JF: Pandemic strain of foot-and-mouth disease virus serotype O. Emerg Infect Dis 2005 11:1887-1893.

17. Valarcher JF, Knowles NJ, Zakharov V, Scherbakov A, Zhang Z, Shang YJ, Liu ZX, Liu XT, Sanyal A, Hemadri D, Tosh C, Rasool TJ, Pattnaik B, Schumann KR, Beckham TR, Linchongsubongkoch W, Ferris NP, Roeder PL, Paton DJ: Multiple origins of foot-and-mouth disease virus serotype Asia 1 outbreaks, 2003-2007. Emerg Infect Dis 2009, 15:1046-1051.

18. Abdul-Hamid NF, Hussein NM, Wadsworth J, Radford AD, Knowles NJ, King DP: Phylogeography of foot-and-mouth disease virus types $\mathrm{O}$ and $\mathrm{A}$ in Malaysia and surrounding countries. Infect Genet Evol 2011, 11:320-328.

19. Abdul-Hamid NF, Firat-Sarac M, Radford AD, Knowles NJ, King DP: Comparative sequence analysis of representative foot-and-mouth disease virus genomes from Southeast Asia. Virus Genes 2011, 43:41-45.

20. de Wit E, Bestebroer TM, Spronken MI, Rimmelzwaan GF, Osterhaus AD, Fouchier RA: Rapid sequencing of the non-coding regions of influenza $A$ virus. J Virol Methods 2007, 139:85-89.

21. Hall TA: BioEdit: a user-friendly biological sequence alignment editor and analysis program for Windows 95/98/NT. Nucl Acids Symp Ser 1999, 41:95-98.

22. Korber B: HIV signature and sequence variation analysis. In Computational and Analysis of HIV Molecular Sequences. Edited by 
Rodrigo AG, Learn GH. Dordrecht, Netherlands: Kluwer Academic Publishers; 2000:55-72.

23. Lole KS, Bollinger RC, Paranjape RS, Gadkari D, Kulkarni SS, Novak NG, Ingersoll R, Sheppard HW, Ray SC: Full-length human immunodeficiency virus type 1 genomes from subtype C-infected seroconverters in India, with evidence of intersubtype recombination. J Virol 1999, 73:152-160.

24. Mathews DH: RNA secondary structure analysis using RNAstructure. Curr Protoc Bioinformatics 2006, Chapter 12:1-14.

25. Matzura O, Wennborg A: RNAdraw: an integrated program for RNA secondary structure calculation and analysis under 32-bit Microsoft Windows. Comput Appl Biosci 1996, 12:247-249.

26. Tamura KPD, Peterson N, Stecher G, Nei M, Kumar S: MEGA5: molecular evolutionary genetics analysis using maximum likelihood, evolutionary distance, and maximum parsimony methods. Mol Biol Evol 2011, 28:2731-2739.

27. Clement M, Posada D, Crandall KA: TCS: a computer program to estimate gene genealogies. Mol Ecol 2000, 9:1657-1659.

28. Rozas J, Sanchez-DelBarrio JC, Messeguer X, Rozas R: DnaSP, DNA polymorphism analyses by the coalescent and other methods. Bioinformatics 2003, 19:2496-2497.

29. Posada D: jModelTest: phylogenetic model averaging. Mol Biol Evol 2008, 25:1253-1256.

30. Drummond AJ, Rambaut A: BEAST: Bayesian evolutionary analysis by sampling trees. BMC Evol Biol 2007, 7:214.

31. Rambaut A, Drummond AJ: Tracer v1.4; 2007. [http://beast.bio.ed.ac.uk/Tracer]

32. Rambaut A: FigTree 1.3.1; 2010. [http://tree.bio.ed.ac.uk/software/figtree/]

33. Orton RJ, Wright CF, Morelli MJ, Juleff N, Thebaud G, Knowles NJ, ValdazoGonzalez B, Paton DJ, King DP, Haydon DT: Observing micro-evolutionary processes of viral populations at multiple scales. Philos Trans $R$ Soc Lond $B$ Biol Sci 2013, 368:20120203.

34. Subramaniam S, Sanyal A, Mohapatra JK, Hemadri D, Pattnaik B: Comparative complete genome analysis of Indian type A foot-and -mouth disease virus field isolates. Virus Genes 2011, 43:224-233.

35. Newton $S E$, Campbell AR, Clarke BE, Rowlands DJ: The sequence of foot-and-mouth disease virus RNA to the $5^{\prime}$ side of the poly(C) tract. Gene 1985, 40:331-336.

36. Clarke BE, Brown EL, Currey KM, Newton SE, Rowlands DJ, Carroll AR: Potential secondary and tertiary structure in the genomic RNAof foot-and-mouth disease virus. Nucleic Acids Res 1987, 15:7067-7079.

37. Mason PW, Pacheco JM, Zhao QZ, Knowles NJ: Comparisons of the complete genomes of Asian, African and European isolates of a recent foot-and-mouth disease virus type $\mathrm{O}$ pandemic strain (PanAsia). J Gen Virol 2003, 84:1583-1593.

doi:10.1186/1297-9716-44-76

Cite this article as: Valdazo-González et al:: Multiple introductions of serotype $O$

foot-and-mouth disease viruses into East Asia in 2010-2011. Veterinary Research 2013 44:76.

\section{Submit your next manuscript to BioMed Central and take full advantage of:}

- Convenient online submission

- Thorough peer review

- No space constraints or color figure charges

- Immediate publication on acceptance

- Inclusion in PubMed, CAS, Scopus and Google Scholar

- Research which is freely available for redistribution 